\title{
Effect of Drying Temperature on the Characteristics of the Lead Zirconium Titanate Powders Prepared by Sol-Gel Process
}

\author{
Tien-I Chang ${ }^{1, *}$, Jow-Lay Huang ${ }^{1, *}$, Jen-Fu Lin ${ }^{1}$, Bing-Huei Chen ${ }^{2}$, Long $\mathrm{Wu}^{2}$, \\ Hong-Ping Lin $^{3}$ and Horng-Hwa $\mathrm{Lu}^{4}$ \\ ${ }^{1}$ Department of Material Science and Engineering, National Cheng-Kung University, \\ No. 1 University Road, Tainan 701, Taiwan, R.O. China \\ ${ }^{2}$ Department of Electrical Engineering, National Cheng-Kung University, \\ No. 1 University Road, Tainan 701, Taiwan, R.O. China \\ ${ }^{3}$ Department of Chemistry, National Cheng-Kung University, No.1 University Road, Tainan 701, Taiwan, R.O. China \\ ${ }^{4}$ Department of Mechanical Engineering, National Chin-Yi Institute of Technology, \\ 35, Lane 215, Section 1, Chung-Shan Road, Taiping City, Taichung County, 411 Taiwan, R.O. China
}

Pure pervoskite phase $\mathrm{Pb}_{1.15}\left(\mathrm{Zr}_{0.53} \mathrm{Ti}_{0.47}\right) \mathrm{O}_{3}(\mathrm{PZT})$ powders were prepared by a chelating acetate sol-gel process. Powders obtained from two different heating temperatures, namely as-dried H.T powders $(573 \mathrm{~K} / 30 \mathrm{~min})$ and as-dried L.T powders $(423 \mathrm{~K} / 10 \mathrm{~h})$ were analyzed. Both the powder samples were investigated by Fourier Transform Infrared Spectroscopy (FT-IR), Differential Thermal Analysis/ Thermal Gravimetric Analysis (DTA/TGA) and Transmission Electron Microscopy (TEM). The combined results indicated that as-dried H.T powders contained a higher mole fraction of acetate groups and that the polycondensation was slower, resulting in a smaller particle size. H.T series is a better, shorter, low-budget, and more energy-economic procedure compared with the conventional heating procedure.

(Received May 24, 2004; Accepted September 14, 2004)

Keywords: lead zirconium titanate, ferroelectrics, sol-gel, morphotropic phase boundary

\section{Introduction}

Lead zirconium titanate (PZT) is an important ferroelectric material possessing good piezoelectric and pyroelectric properties with important technological applications. ${ }^{1-3)}$ It has been used widely since the 1950 s in electronic components and devices such as ultrasonic-audio tone transducers, electrical resonators, wave filters, sensors and actuators. It is known that PZT has a non-centrosymmetric $\mathrm{ABO}_{3}$ perovskite type structure. The piezoelectric activity in the $\mathrm{PbZrO}_{3}$ $\mathrm{PbTiO}_{3}$ solid solution system is optimum for compositions near the morphotropic phase boundary (MPB). The MPB is an almost-temperature-independent phase boundary that separates the two ferroelectric phases: the tetragonal phase $\left(\mathrm{F}_{\mathrm{T}}, \mathrm{P} 4 \mathrm{~mm}\right)$ and the rhombohedral phase $\left(\mathrm{F}_{\mathrm{R}}, \mathrm{R} 3 \mathrm{c}\right)$.

The coexistance of phases occurs due to a compositional fluctuation (different chemical potential caused by nonhomogeneity) of $\mathrm{Zr}^{+4}$ and $\mathrm{Ti}^{+4}$ ions in the PZT structure. Compositions near the MPB may have both of those phases coexisting to give a total of fourteen possible polarization directions (six tetragonal $\langle 001\rangle$ and eight rhombohedral $\langle 111\rangle$ in reference to the cubic prototype cell axes). The large numbers of polarization directions enable optimized crystallographic orientations to be established from grain to grain in the polarization process and, in turn, result in very high pizoelectric properties. In the preparation of lead zirconium titanate, the control of some parameters is important to achieve the desired material properties. These parameters include the absence of intermediate crystalline phase like

\footnotetext{
${ }^{*}$ Corresponding author,

E-mail: takashi@cubic.mat.ncku.edu.tw,JLH888@mail.ncku.edu.tw,

Postal address: No. 29, Dongfong Rd., North District, Tainan City 704,

Taiwan, R.O. China
}

pyrochlore phase as well as a homogeneous lead distribution in the microstructure.

For the solid-state reaction method, due to intermediate reactions leading to the formation of $\mathrm{PbTiO}_{3}$ (PT) and $\mathrm{PbZrO}_{3}(\mathrm{PZ})$, the PZT formed by this method is heterogeneous in composition. However, the PZT powder synthesized by chemical methods such as sol-gel process has resulted in powder with low compositional fluctuation, narrow MPB, and highreactivity. ${ }^{4-6)}$

In recent years, there has been a considerable interest in using the sol-gel process to prepare ceramics and glasses from metal alkoxides. ${ }^{7-9)}$ The sol-gel process can be used to produce high purity, ultra-fine particles and large-area thin films at relatively low temperatures. The properties of the resulting PZT powders depend on the choice of metal alkoxides and solvents, solution concentration, $\mathrm{Zr}$ to Ti ratio as well as the drying rate or temperature.

The common precursors for the sol-gel preparation of ferroelectrics are metal alkoxides. Metal alkoxides are soluble in common solvents and can be polymerized through hydrolysis and condensation. In particular, lead acetate trihydrate $\left[\mathrm{Pb}\left(\mathrm{CH}_{3} \mathrm{CO}_{2}\right)_{2} .3 \mathrm{H}_{2} \mathrm{O}\right]$ is chosen as a precursor for lead because lead alkoxides are unstable and are not soluble in common solvents.

In practice, the alkoxide solution is stabilized against uncontrolled hydrolysis by chemical modification, or by the introduction of chelating agents to produce a number of active functional groups and thereby lower its reactivity with water. Examples of chemical modifiers are 2-methoxyethanol (2-MOE) and acetic acid. In this study, we used acetic acid as a modifier. This carboxylic acid does not only behave as an acid catalyst, but also as a ligand and changes the alkoxide precursors at the molecular level and thereby modifying the whole hydrolysis condensation process. 
Several studies have demonstrated that sol-gel derived PZT powders need to be dried in two or more stages in order to remove the solvent completely. And several researchers ${ }^{13-17)}$ have reported the DTA/TGA analysis about the endothermic peak at $150^{\circ} \mathrm{C}$ is attributed to the evaporation of low boiling point solvents and the exothermic peak at about $300 \sim 380^{\circ} \mathrm{C}$ is attributed to the decomposition of organic compounds. Fewer studies have focused on the effect of drying conditions at $150^{\circ} \mathrm{C}$ and $300^{\circ} \mathrm{C}$ on the properties of PZT ceramics.

In this study, the PZT powder was prepared by using zirconium n-propoxide, titanium iso-propoxide and lead acetate trihydrate as precursor. The solution obtained from sol-gel process was identified by NMR, and the bonding conditions were analyzed by FT-IR. The phase transformation of $\mathrm{Pb}_{1.15}\left(\mathrm{Zr}_{0.53} \mathrm{Ti}_{0.47}\right) \mathrm{O}_{3}$ powders with temperature was studied by differential thermal analysis (DTA) and thermogravimetric analysis (TGA). The crystal structures of calcined PZT powders were identified by Rigaku X-ray diffractometer (XRD) with $\mathrm{Cu} \mathrm{K} \alpha$ radiation $(\lambda=$ $0.15418 \mathrm{~nm}$ ) and a scanning step of $4^{\circ} / \mathrm{min}$ and $2 \theta$ angle from 20 to $60^{\circ}$. Compared with the conventional powderproducing process (i.e. L.T powders), a higher temperature and shorter procedure period (i.e. H.T powders) have been used as a new powder-producing condition to compare the difference of the particles size distribution and phase transformation temperatures.

\section{Experimental Procedures}

Figure 1 shows the experimental procedure of the present study. Lead acetate trihydrate $(0.01 \mathrm{~kg})$ was first dissolved in $1 \mathrm{~mL}$ of propyl alcohol (ACROS Organics, density $800 \mathrm{~kg}$ / $\mathrm{m}^{3}$, purity $99 \%$ ) at $353 \mathrm{~K}$ in a three-neck reaction glass container. The solution was then heated to $393 \mathrm{~K}$ and maintained for $2 \mathrm{~h}$ to remove the residual water, and naturally

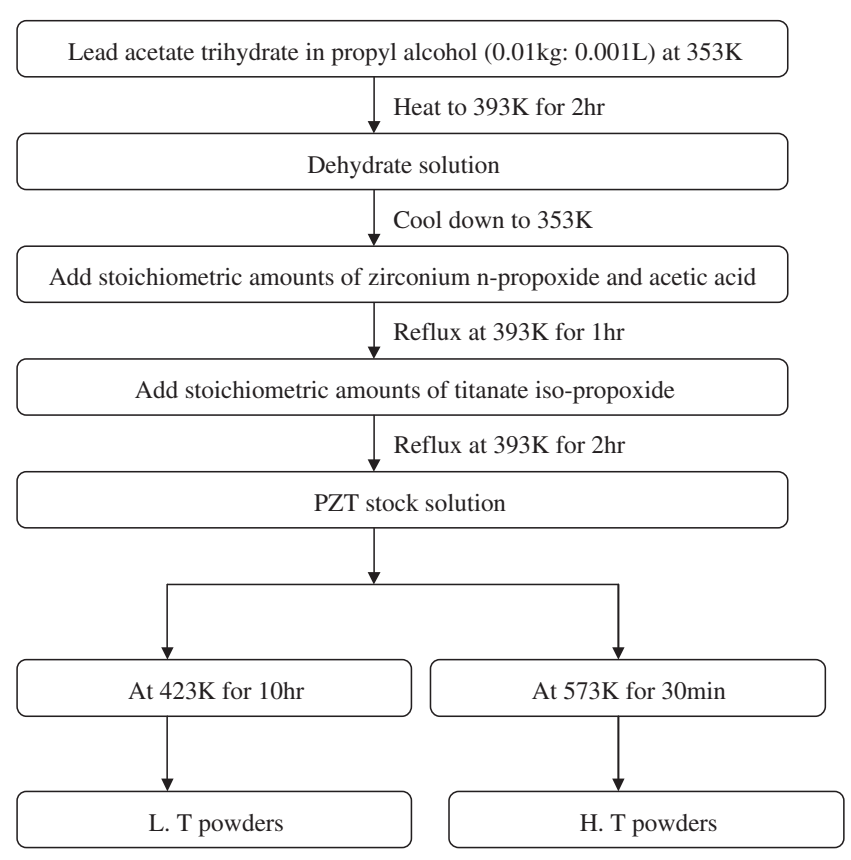

Fig. 1 Flow-chart for preparation of the PZT (53/47) stock solution, H.T and L.T powders. cooled to $353 \mathrm{~K}$. Stoichiometric amounts of zirconium npropoxide (density $1050 \mathrm{~kg} / \mathrm{m}^{3}$, purity $75 \%$ ) and acetic acid (TEDIA, density $1059 \mathrm{~kg} / \mathrm{m}^{3}$ ) were added to the lead acetate solution and refluxed at $393 \mathrm{~K}$ for $1 \mathrm{~h}$ to form PZ solution. The ratio of lead acetate to acetic acid to propyl alcohol was 10:5:1. Titanium iso-propoxide (density $755 \mathrm{~kg} / \mathrm{m}^{3}$, purity 98\%) was added to the PZ solution and further refluxed at $393 \mathrm{~K}$ for $2 \mathrm{~h}$, to form the PZT solution. NMR analysis of asprepared PZT solution was performed by using a $\mathrm{C}^{13} \mathrm{NMR}$ spectrum in deuterated benzene $\left(\mathrm{C}_{6} \mathrm{D}_{6}\right)$.

The PZT stock solution was used to produce the hightemperature powder; namely H.T powders (i.e. drying at $573 \mathrm{~K}$ for $30 \mathrm{~min}$ to remove the acetate group $)^{18)}$ and lowtemperature powders; namely L.T powders (i.e. drying at $423 \mathrm{~K}$ for $10 \mathrm{~h}$ ). FT-IR spectra of as-dried PZT powders were obtained by using a JASCO FT-IR-460 plus in the range of the 400 to $4000 \mathrm{~cm}^{-1}$.

After that, H.T. and L.T. powders were characterized with a laser particle size distribution analyzer (Malvern Instruments) and Transmission Electron Microscope (HITACHI FE-2000 Field Emission Transmission Electron Microscope). Phase transformations of powders were carried out by DTA/ TGA by using $\mathrm{Al}_{2} \mathrm{O}_{3}$ as the reference.

\section{Results and Discussion}

\section{1 $\mathrm{C}^{\mathbf{1 3}} \mathrm{NMR}$ analysis}

Figure 2 shows the $\mathrm{C}^{13}$ NMR spectrum of the as-prepared PZT solution in deuterated benzene $\left(\mathrm{C}_{6} \mathrm{D}_{6}\right)$. The resonance peak at 10.39, 25.94, 64.01, and $178.04 \mathrm{ppm}$ can be attributed to the carbon bonds of both the propyl alcohol and acetic acid, and designated by "a" to "d". According to the NMR index, the peaks at $128 \mathrm{ppm}(127.77,128.01,128.25 \mathrm{ppm})$ were due to the deuterated benzene $\left(\mathrm{C}_{6} \mathrm{D}_{6}\right)$. The peak at $172.14 \mathrm{ppm}$ (designated as "e") may be attributed to the formation of a small amount of ester, a by-product during the polymeric reaction.

The origin of this ester is apparent considering the reactions involved in the preparation of the lead precursor. It has been determined that in the synthesis route followed, one alkoxy group replaces one of the acetate groups as:

$$
\begin{aligned}
& \mathrm{Pb}(\mathrm{OAc})_{2}+\mathrm{ROH} \rightarrow \mathrm{Pb}(\mathrm{OAc})(\mathrm{OR})+\mathrm{AcOH} \\
& \text { Where } \mathrm{R}=\mathrm{CH}_{3} \mathrm{CH}_{2} \mathrm{CH}_{2-}, \quad \text { and } \mathrm{Ac}=\mathrm{CH}_{3} \mathrm{CO}-
\end{aligned}
$$

The AcOH reacts with the solvent propyl alcohol to form an ester:

$$
\mathrm{AcOH}+\mathrm{ROH} \rightarrow \mathrm{AcOR}+\mathrm{H}_{2} \mathrm{O}
$$

It releases a certain amount of free water into the system. If this free water is not removed by distillation, some preliminary hydrolysis and condensation reactions can occur on combining with the $\mathrm{Zr}$ / Ti precursor solution leading to a degree of in-homogeneity in the solution. ${ }^{10)}$ As mentioned above, after dissolving lead acetate trihydrate in propyl alcohol at $353 \mathrm{~K}$, it is necessary to dehydrate the lead acetic solution.

Acetic acid reacts with zirconium propoxide and titanium isopropoxide to form titanium isopropoxide monoacetate and zirconium propoxide diacetate, respectively. ${ }^{11)}$ The alcohol formed in the reaction also reacts with acetic acid to produce 
(a)

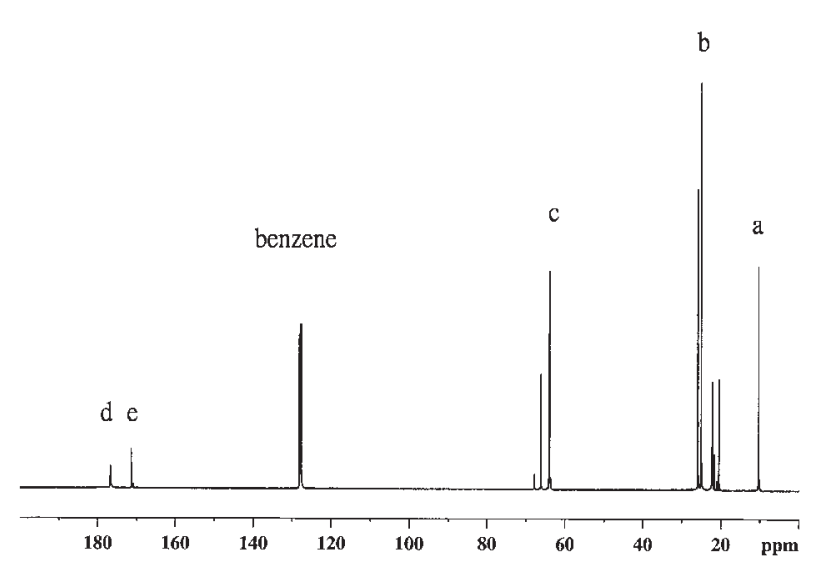

(b)

$\begin{array}{cccc}\mathrm{H} & \mathrm{H} & \mathrm{H} \\ \mathrm{a} & \mathrm{b}|\mathrm{C}| \\ \mathrm{a}-\mathrm{C}-\mathrm{C}-\mathrm{C}-\mathrm{OH} \quad \text { propgl alcohol } \\ \mathrm{a}=10.39 \mathrm{ppm} \\ \mathrm{c}=64.01 \mathrm{ppm}\end{array}$

Fig. $2 C^{13}$ NMR spectrum of (a) the as-prepared PZT (53/47) solution and (b) peaks relative to the bondings.

esters. The acetate group likely act as bridging ligands bonded to two metal ions to form structures such as bridging structure of titanium or zirconium alkoxide acetate. ${ }^{12)}$

\subsection{DTA/TGA analysis}

DTA/TGA was performed on the H.T and L.T powders at a heating rate of $10 \mathrm{~K} / \mathrm{min}$. The DTA curve shows an endothermic peak at $373 \mathrm{~K}$ for H.T powders and $362 \mathrm{~K}$ for L.T powders (Fig. 3(a)), primarily due to the removal of alcohol and water absorbed in the PZT solution. The exothermic peak at $598 \mathrm{~K}$ (H.T powders) and $592 \mathrm{~K}$ (L.T powders) together with the corresponding larger weight loss (Fig. 3(b)), can be attributed to the decomposition of the residual lead acetate. ${ }^{13)}$

As to the broadened exothermic peaks from 773 to $788 \mathrm{~K}$ for H.T and L.T powders, it should be attributed to the bond breaking reaction in the PZT polymer or the formation of inorganic ceramic phase. The exothermic peaks at $823 \mathrm{~K} \sim 853 \mathrm{~K}$ for H.T and $823 \mathrm{~K}$ for L.T powders should be correlated to the phase transition of PZT, because no weight loss could be found in the TG curve. As a result, crystallization of PZT powders takes place at the range of 773 to $788 \mathrm{~K}$, and perovskite structure is established above $823 \mathrm{~K}$ for H.T powders and for L.T powders. Those were also
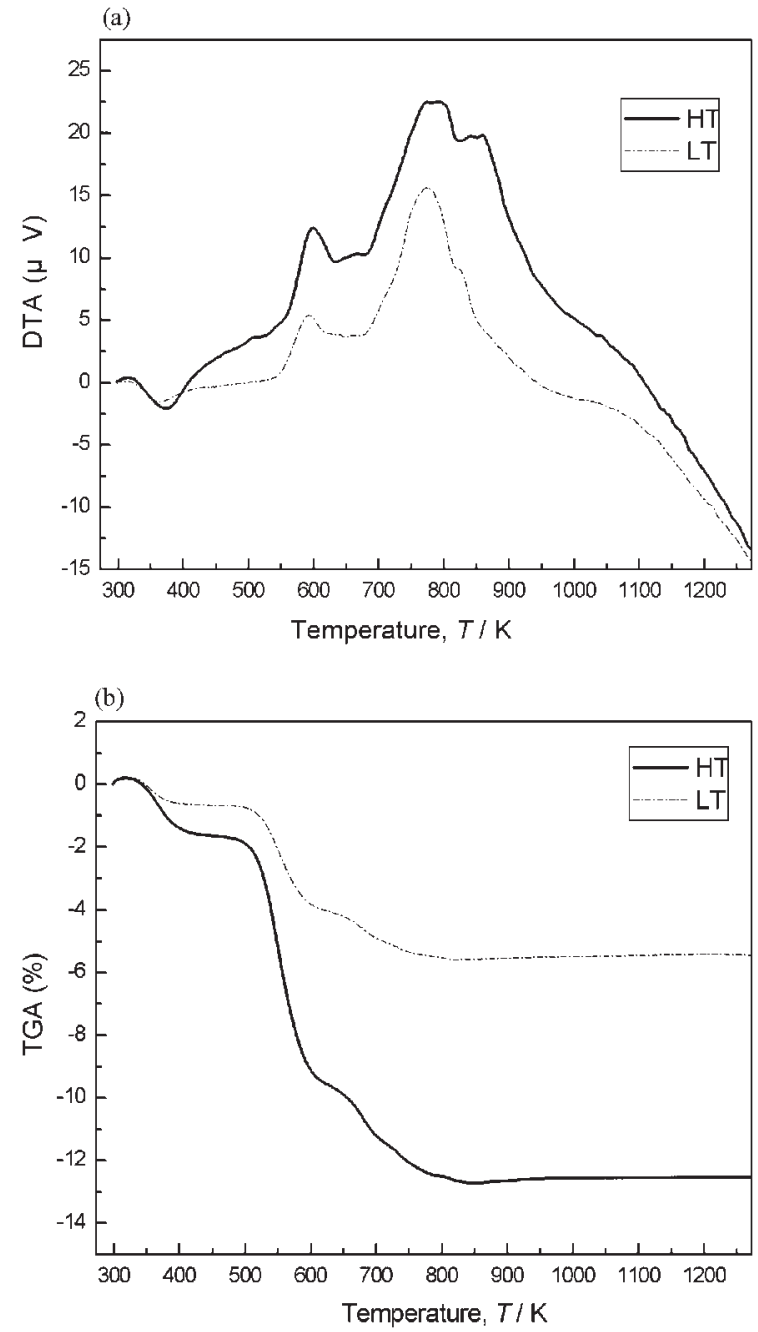

Fig. 3 (a) DTA and (b) TG results of the H.T and L.T PZT (53/47) powders.

proved by the XRD patterns of the H.T and L.T powders calcined at various temperatures for $30 \mathrm{~min}$ as shown in Fig. 4. Taking these observations into consideration, the first exothermic peak is considered to be predominantly caused by the formation of the meta-stable pyrochlore phase and the second one by the perovskite phase formation, both accompanied by the residual combustion of the organics. For many sol-gel-derived PZT powders, ${ }^{13-17)}$ the observed crystallization of pyroclore phase at temperatures between $723 \mathrm{~K}$ and $773 \mathrm{~K}$ and its transformation to the perovskite phase in the temperature range from 773 to $873 \mathrm{~K}$, are quite typical. The individual temperatures where the DTA peaks appear depend on the precursor chemistry. ${ }^{13-17)}$ Above $873 \mathrm{~K}$, the TGA curve shows no significant decrease in weight. Therefore, the starting temperature for calcination is estimated to be $873 \mathrm{~K}$, which was chosen as the calcined temperature of the powders.

The total weight loss observed in the TGA analysis (Fig. 3(b)) shows that the as-dried H.T powder contained 88 mass\% PZT, and the as-dried L.T powder contained 95 mass\% PZT. Therefore, the as-dried H.T powder contained more organic species. The biggest portion of organic species should be the acetate group, because the heating period $(30 \mathrm{~min})$ is shorter for as-dried H.T powder than that 
(a)

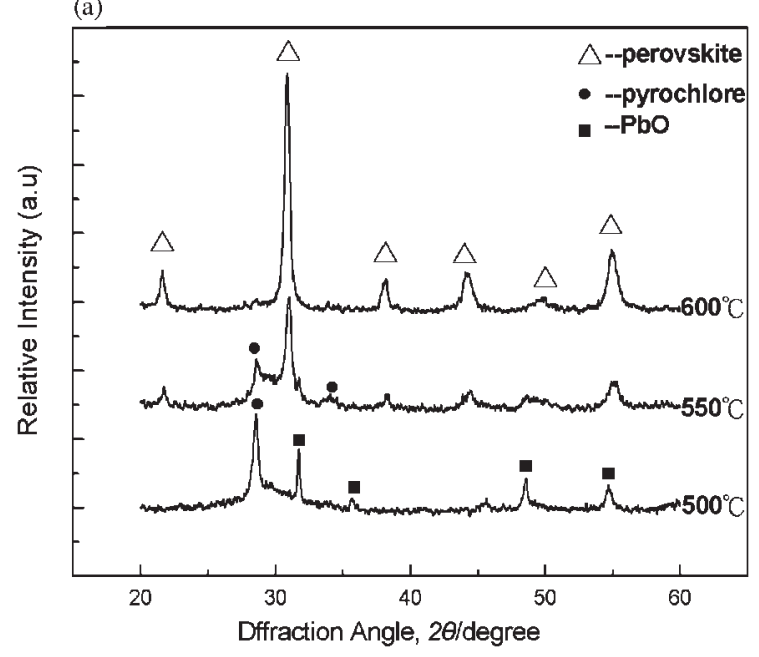

(b)

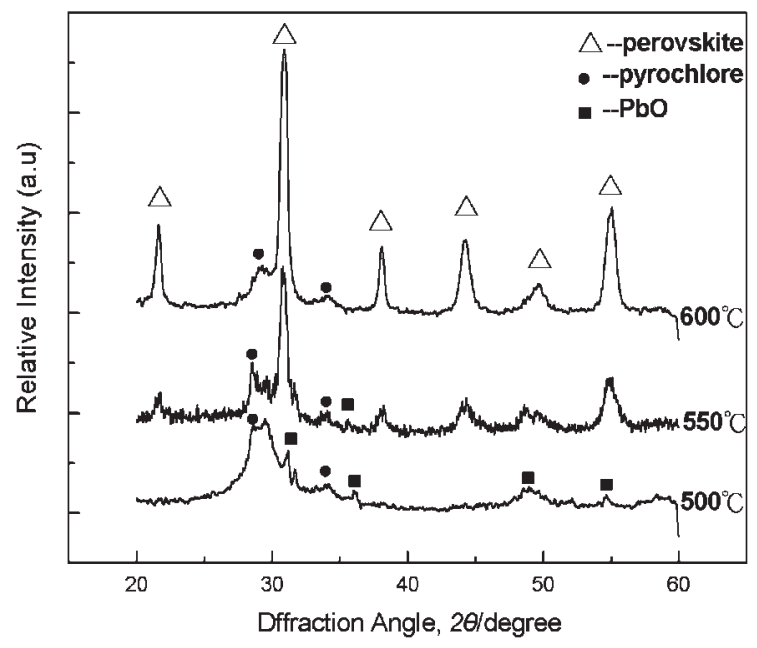

Fig. 4 XRD patterns of (a) the H.T and (b) L.T powders calcined at various temperatures for $30 \mathrm{~min}$.

$(10 \mathrm{~h})$ for as-dried L.T powder. Yang ${ }^{14)}$ stated that the higher amount of acetate groups in the gel structure is responsible for an increased distance between the cations $\left(\mathrm{Pb}^{2+}, \mathrm{Zr}^{4+}\right.$, and $\left.\mathrm{Ti}^{4+}\right)$ in the structure. This results in an inhibition of the formation of PZT for H.T powder. This necessitates a higher reaction temperature for the formation of $\mathrm{PZT}$.

Also, it was observed that for H.T powders all DTA peaks correspond to temperatures higher than those for L.T powders. It is due to incomplete removal of organic solvent during the drying process of H.T powders. But for L.T powders, it takes longer time to produce fewer amounts of organic. It can be also confirmed from FT-IR analysis as discussed in 3-3.

\subsection{FT-IR analysis}

The FT-IR technique was employed to monitor the chemistry of the aqueous acetate-based process. Figure 5(a) shows the FT-IR results of the PZT stock solution. Since titanium isopropoxide monoacetate and zirconium propoxide diacetate were formed from titanium iso-propoxide, zirconium propoxide, and acetic acid, the PZT stock solution should contain lead acetate, titanium isopropoxide monoacetate and zirconium propoxide diacetate, the excess acetic

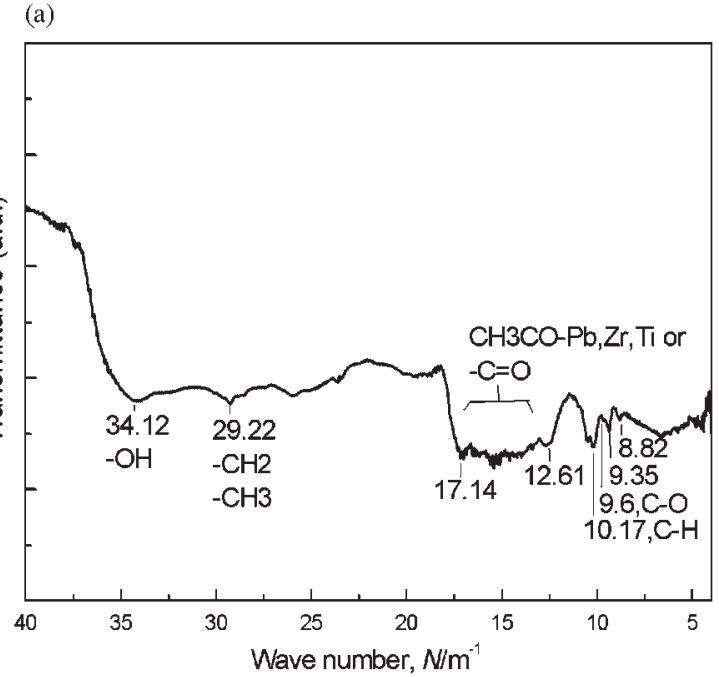

(b)

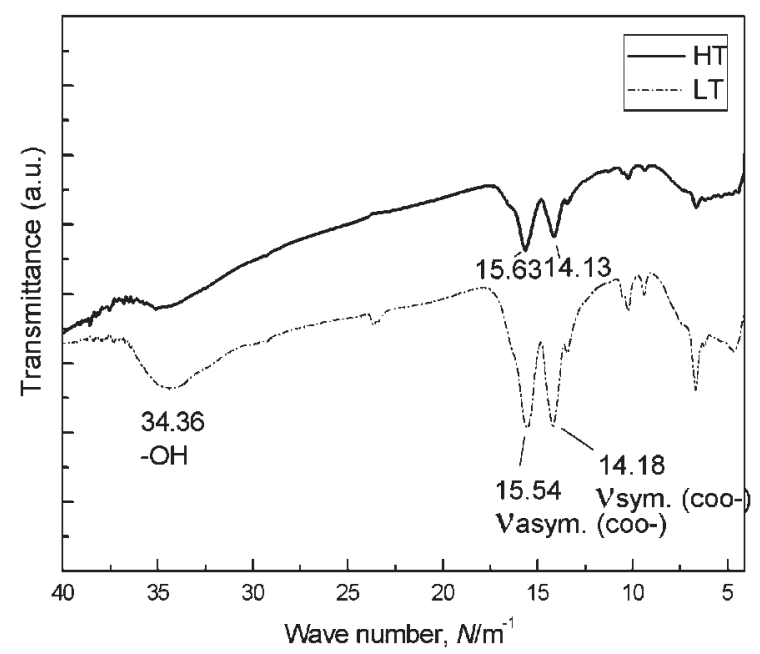

Fig. 5 FT-IR spectrums of (a) a new made PZT solution and (b) the H.T and L.T powders before calcinations.

acid and water, a trace amount of un-reacted titanium isopropoxide, and also the product of isopropanol.

The spectral assignment can be made as follows: (1) The broad band extending from 3600 to $2800 \mathrm{~cm}^{-1}$ can be assigned to the stretching modes of $v_{\mathrm{OH}}$ and $v_{\mathrm{CH} 2, \mathrm{CH} 3}$ of isopropanol, water, acetic acid, and acetate organic moieties. (2) Two bands around $1714 \mathrm{~cm}^{-1}$ and $1261 \mathrm{~cm}^{-1}$ could be attributed to the $v$ (coo-) vibrations of an acetate ligand but the large frequency separation $\left(\Delta v=453 \mathrm{~cm}^{-1}\right)$ between the $v_{\text {sym }}\left(1261 \mathrm{~cm}^{-1}\right)$ and the $v_{\text {asym }}\left(1714 \mathrm{~cm}^{-1}\right)$ suggests an unidentate acetate ligand.

The FT-IR spectroscopy was also used to monitor the powder formation steps at different temperatures. Figure 5(b) shows the FT-IR spectra of H.T and L.T powders before calcination. It is found that both of them have the same bonding condition and similar characteristics to the spectra obtained by Yang. ${ }^{14)}$ The broad bands at approximately $3436 \mathrm{~cm}^{-1}$ are attributed to $\mathrm{OH}$ stretching vibrations due to $\mathrm{H}_{2} \mathrm{O}$ and hydroxyls present in the systems. There were two absorption bands in the vicinities of 1413 and $1563 \mathrm{~cm}^{-1}$ for H.T powder and 1418 and $1554 \mathrm{~cm}^{-1}$ for L.T powder (Fig. 5(b)). These peaks were attributed to the symmetric 
$\left(v_{\text {sym }}(\right.$ coo- $\left.)\right)$ and asymmetric $\left(v_{\text {asym }}(\right.$ coo- $\left.)\right)$ vibrations of the acetate group, respectively. The free acetate ion has 15 infrared active fundamentals of which the asymmetric and symmetric stretching modes of the coo- group have been selected for structural studies. For the free acetate ion, the $v_{\text {asym }}$ (coo-) and $v_{\text {sym }}$ (coo-) are located approximately at $1560 \mathrm{~cm}^{-1}$ and $1416 \mathrm{~cm}^{-1}$, respectively, giving $\Delta$ (free) $\sim 144 \mathrm{~cm}^{-1}\left(\Delta v, \Delta v=\Delta\left(v_{\text {asym }}-v_{\text {sym }}\right)\right)$. ${ }^{18)}$ When the difference between those two absorption peaks $\Delta v$ is smaller than the ionic values, acetate is typically a chelating bidentate ligand. When $\Delta v$ is larger than that of cheating bidentate ligand and close to the ionic values, the acetate group is typically a bridging bidentate ligand. ${ }^{18,19)}$

The value of $\Delta v$ was $150 \mathrm{~cm}^{-1}$ for H.T powder (Fig. 5(b)), and $136 \mathrm{~cm}^{-1}$ for L.T powder (Fig. 5(b)). The difference $\Delta v$ of H.T powder was larger than that of the L.T powder, meaning that the H.T powder contained more bridging bidentate ligands and the L.T powder contained more chelating bidentate ligands.

\subsection{Distribution of particles size for as-dried H.T and L.T powders}

The H.T powders and L.T powders were characterized with a laser particle size distribution analyzer. The results are shown in Fig. 6. Comparing the particle size distribution of the two different heating conditions, the L.T powders (Fig. 6(b)), in which the powders contained fewer acetate group as shown in the DTA/TG results of Fig. 3(b), was found to be less homogeneous $(491.5 \mathrm{~nm}$ and $1083.7 \mathrm{~nm})$. It also had larger aggregate particle sizes compared with asdried H.T powders (421.2 nm) (Fig. 6(a)).

Brunckova et al. ${ }^{20)}$ indicate that the acetate group inhibits the polycondensation process and if the chelating acetate groups are present, the structure around the Ti-ions remains intact which was proved in the 3.3 FT-IR section, resulting in an inhibition of the condensation process, prolonging the time of gelation. Since the rate of hydrolysis and polycondensation control the aggregate particle size of the precursor sol, a slower rate of polycondensation should lead to the formation of a more monodispersed gel with a smaller aggregate particle size. Indeed the H.T powders, which contain a larger portion of organic species, exhibited inhibited powder formation compared with the L.T powders. The H.T powders were, therefore, more homogeneous, and a smaller aggregate in particle size.

\subsection{TEM analysis of the as-dried powders}

The H.T and L.T as-dried powders were analyzed by TEM (Fig. 7). Electron diffraction patterns for the H.T and L.T powders show the amorphous phase. TEM analysis enables the primary particle size of the powders to be determined, as opposed to the particle size distribution given by laser diffraction (Figs. 6(a) (b)). The primary particles of the H.T powders were approximately $300-400 \mathrm{~nm}$ in diameter (Fig. 7(a)), compared to the L.T powders which were about $400 \mathrm{~nm}$ or larger in diameter (Fig. 7(b)). For the H.T powders, the smaller particles size could decrease the sintering temperatures. Also, the results are in a good agreement with the particle size distribution determined by laser diffraction.
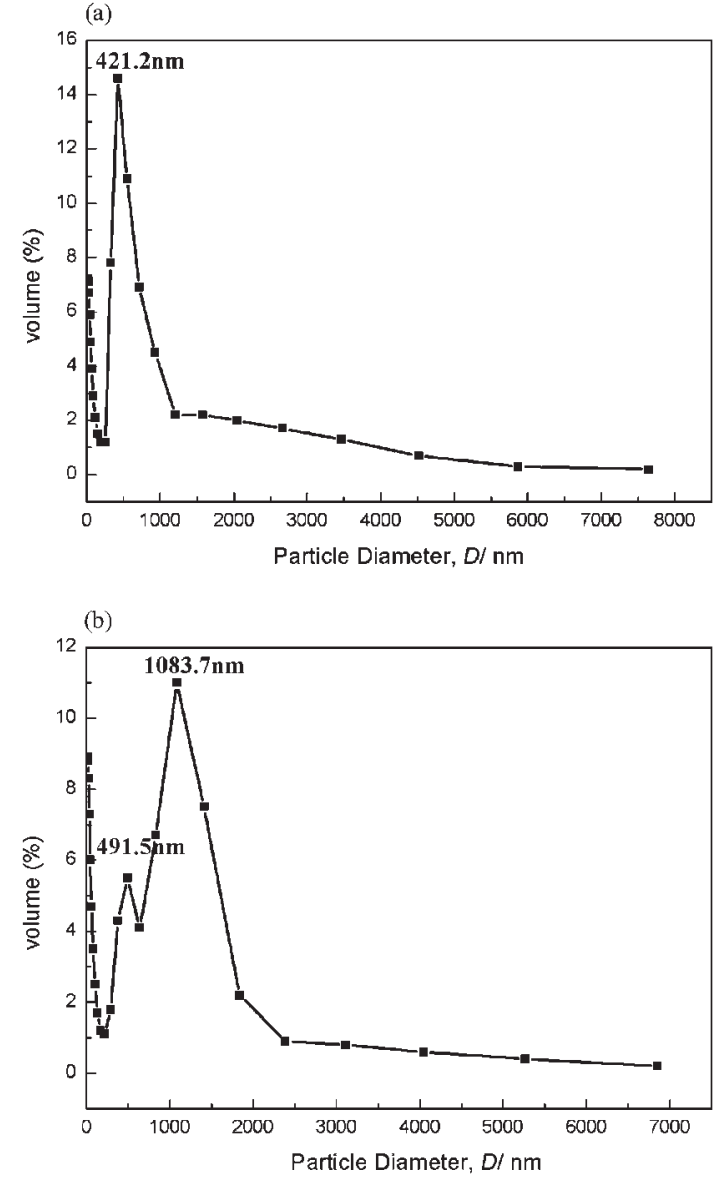

Fig. 6 The particle size distributions of (a) the H.T and (b) L.T Powders.

\section{Conclusions}

(1) The DTA curve shows an endothermic peak at $373 \mathrm{~K}$ for H.T powders and $362 \mathrm{~K}$ for L.T powders, primarily due to the removal of alcohol and water absorbed in the PZT solution. The exothermic peak at $598 \mathrm{~K}$ (H.T powders) and $592 \mathrm{~K}$ (L.T powders) together with the corresponding weight loss, can be attributed to the decomposition of the residual lead acetate and the formation of carbonate. Above $873 \mathrm{~K}$, the TGA curve does not show any significant decrease in weight and this is the starting temperature, which was chosen as the calcined temperature of the powders.

(2) The FT-IR spectroscopy results show a comparison of H.T powders and L.T powders. The difference $\Delta v$ of the H.T powder was larger than that of the L.T powder, meaning that the H.T powder contained more bridging bidentate ligands and the L.T powder contained more chelating bidentate ligands.

(3) Comparing the particle size distribution of the two different heating conditions of as-dried powders, the L.T powders, in which the powders contained fewer acetate group as shown in the DTA/TG results, was found to be less homogeneous $(491.5 \mathrm{~nm}$ and $1083.7 \mathrm{~nm})$. It also had larger aggregate particle sizes compared with as-dried H.T powders (421.2 nm). Therefore, for H.T powders with homogeneous distribution, this new procedure will be a better heating condition for further studies. 
(a)
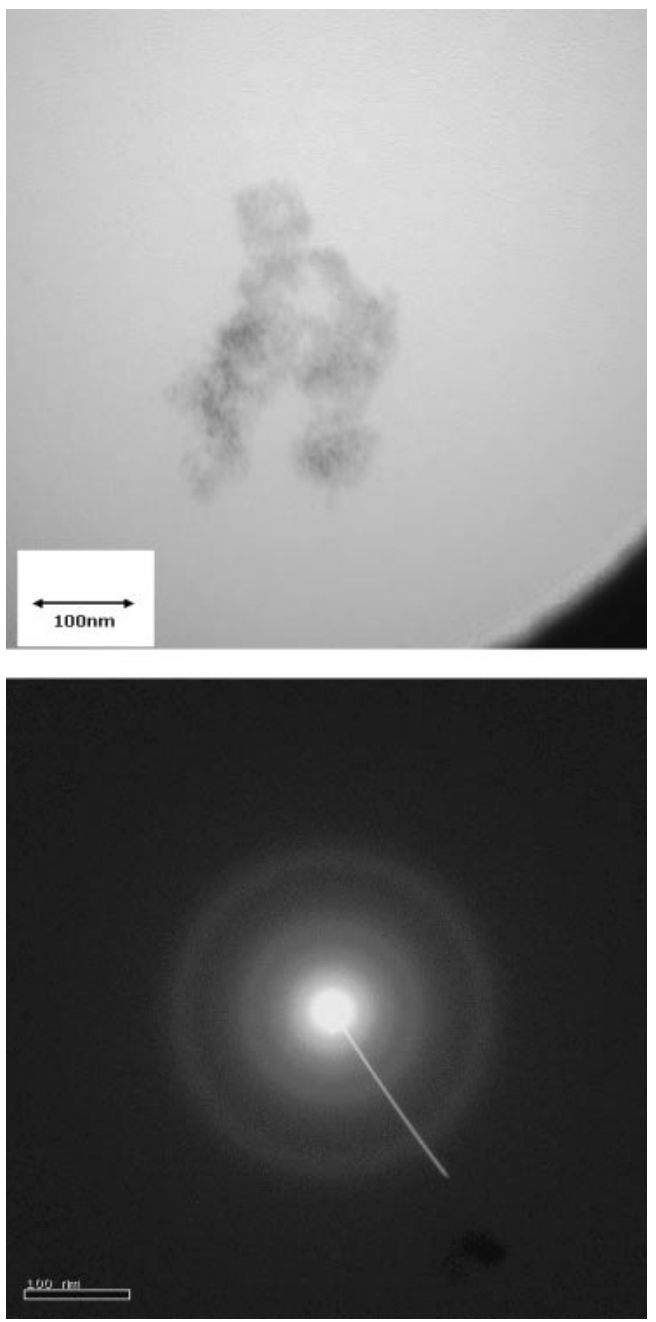

(b)
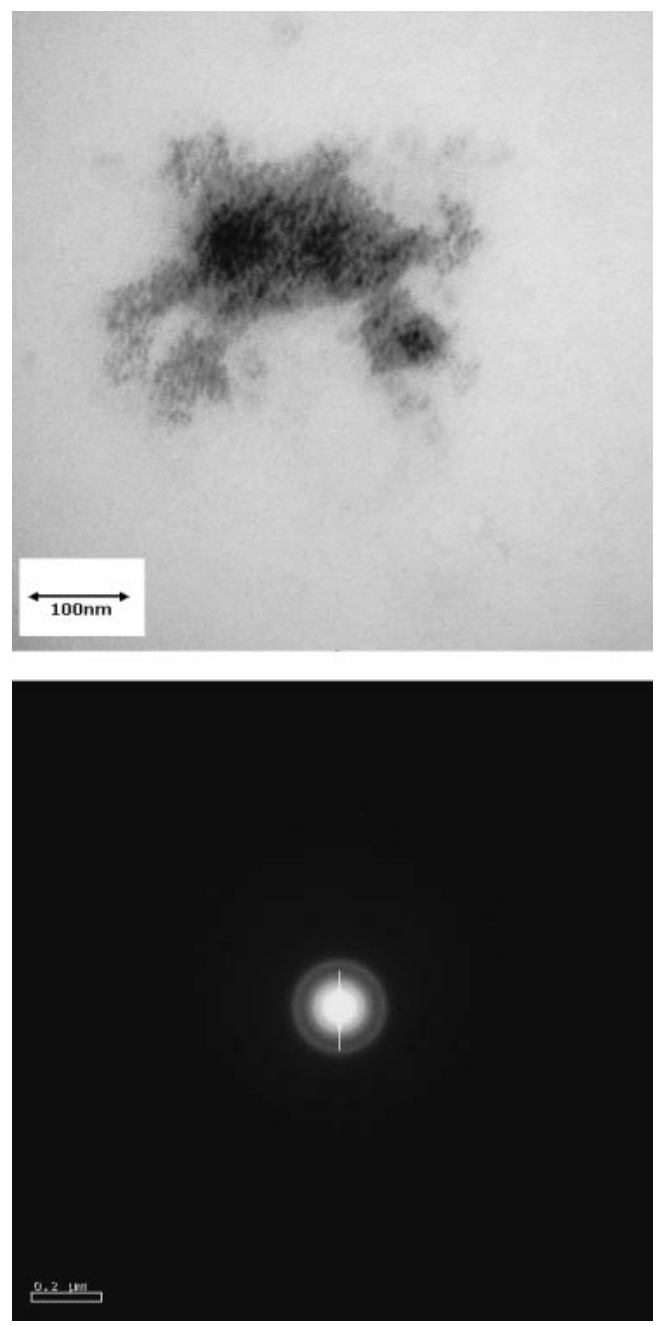

Fig. 7 Bright field TEM micrographs and corresponding electron diffraction patterns for (a) the H.T and (b) L.T powders.

\section{Acknowledgment}

The authors would like to thank the National Science Council of the Taiwan, Republic of China, for its financial support under Contract No. NSC 91-2216-E006-042.

\section{REFERENCES}

1) H. Kanai, O. Furukawa, H. Abe and Y. Yamashita: J. Am. Ceram. Soc. 77 (1994) 2620-2624.

2) D. V. Taylor and D. Damjanovic: Appl. Phys. Lett. 76 (2000) 16151617.

3) L. M. Levinson: Electric Ceramics Properties, Devices, Applications, (Marcel Dekker, New York, 1987) pp. 371-492.

4) M. A. Zaghete, C. O. Paiva-Santos, J. A. Varela, E. Longo and Y. P. Mascarenhas: J. Am. Ceram. Soc. 75 (1992) 2089-2093.

5) G. ToimandlT, A. Stiegelschmitt and R. Bohner: Science of Ceramic Chemical Processing, Part 1, Sol-Gel Science, ed. L. L. Hench and D. R. Ultrich, (Wiley, New York, 1986) pp. 56-60.

6) K. Kakegawa, K. Arai, Y. Sasaki and T. Tomizawa: J. Am. Ceram. Soc. 71 (1988) C49-C52.

7) M. L. Calzada, R. Sirera, F. Carmona and B. Jimenez: J. Am. Ceram. Soc. 78 (1995) 1802-1808.

8) T.-M. Susan, J. Chen, K. Vedam and R. E. Newnham: J. Am. Ceram.
Soc. 78 (1995) 1907-1913.

9) Y.-I. Park, M. Nagai, M. Miyayama and T. Kudo: J. Mater. Sci. 36 (2001) 1995-2000.

10) C. D. E. Lakeman and D. A. Payne: J. Am. Ceram. Soc. 75 (1992) 3091-3096.

11) L. C. Klein: Sol-Gel Optics: Processing and Applications, (Kluwer Academic Publishers, London, 1994) pp. 260-264.

12) C. Sanchez, P. Toledano and F. Ribot: Better Ceramics through Chemistry, Volume 4, ed. B. J. J. Zelinski, D. E. Clark and D. R. Ulrich, (San Francisco, Material Research Society, 1990) pp. 47-59.

13) P. R. Coffman, C. K. Barlingay, A. Gupta and S. K. Dey: J. Sol-gel Sci. and Tech. 6 (1996) 83-106.

14) W. D. Yang: Ceram. Inter. 27 (2001) 373-384.

15) H. Hirashima, E. Onishi and M. Nakawaga: J. Non-Cryst. Solids 121 (1990) 404-406.

16) C. T. Lin, B. W. Scanlan, J. D. Mcneill, J. S. Webb and L. Li: J. Mater. Res. 7 (1992) 2546-2554.

17) T. Fukui, C. Sakurai and M. Okuyama: J. Mater. Res. 7 (1992) 791794.

18) S. Doeuff, M. Honry, C. Sanchez and J. Livage: J. Non-Cryst. Solids 89 (1987) 206-216.

19) K. Nakamoto: Infrared and Raman Spectra of Inorganic and Coordination compounds, (fourth edition, John Wiley and Sons, New York, 1986) pp. 231-233.

20) J. Livage, C. Canchez, M. Henry and S. Doeuff: Solid State Chem. 32/33 (1989) 633-638. 